\title{
Technology enablers for the implementation of Industry 4.0 to traditional manufacturing sectors: a review
}

\author{
Antonio Jimeno-Morenilla ${ }^{1 *}$, Philip Azariadis ${ }^{2}$, Rafael Molina-Carmona ${ }^{3}$, Sofia Kyratzi ${ }^{2}$, \\ Vassilis Moulianitis ${ }^{2}$
}

\author{
${ }^{1}$ Department of Computer Technology, University of Alicante, Spain \\ ${ }^{2}$ Department of Product \& Systems Design Engineering, University of the Aegean, Greece \\ ${ }^{3}$ Department of Computer Science and Artificial Intelligence, University of Alicante, Spain \\ "corresponding author's email: jimeno@dtic.ua.es
}

\begin{abstract}
The traditional manufacturing sectors (footwear, textiles and clothing, furniture and toys, among others) are based on small and medium enterprises with limited capacity on investing in modern production technologies. Although these sectors rely heavily on product customization and short manufacturing cycles, they are still not able to take full advantage of the fourth industrial revolution. Industry 4.0 surfaced to address the current challenges of shorter product life-cycles, highly customized products and stiff global competition. The new manufacturing paradigm supports the development of modular factory structures within a computerized Internet of Things environment. With Industry 4.0, rigid planning and production processes can be revolutionized. However, the computerization of manufacturing has a high degree of complexity and its implementation tends to be expensive, which goes against the reality of SMEs that power the traditional sectors. This paper reviews the main scientific-technological advances that have been developed in recent years in traditional sectors with the aim of facilitating the transition to the new industry standard.
\end{abstract}

Keywords: Industry 4.0; Traditional sectors; SMEs; Technology enablers; IoT; Cloud manufacturing.

\section{Introduction}

Industry 4.0 (also referred to as Intelligent Industry or Cyberindustry) represents a new way of organizing the methods of production. This new concept of industrial structure was first introduced at the Hanover Fair in 2011. The aim is to set up a large number of "smart factories" capable of greater adaptability to production needs and processes, as well as a more efficient allocation of resources. It is based on a number of emerging technologies and approaches like the Internet of Things (IoT), Cyberphysical Systems, Culture maker (Do-ItYourself Culture), Factory 4.0, etc. Industry 4.0 is embracing the idea of a growing and adequate digitalization and cooperative coordination in all the productive sectors of the economy.

\subsection{Technology enablers for Industry 4.0 in traditional manufacturing sectors}

In this new scenario, traditional manufacturing sectors (footwear, textiles and clothing, furniture, toys, etc.) face many challenges. It is important for these companies to achieve their transformation from machine dominant manufacturing to digital manufacturing. They should clearly review their position and respective potential against basic requirements set 
forward by Industry 4.0, and therefore, generate and adapt a well-defined road map. Technological enablers make it easier for industry to adopt to the "smart factories" scenario.

The traditional sectors are based on small and medium enterprises (SMEs) with limited capacity on investing in modern production technologies. These sectors rely heavily on product customization and short manufacturing cycles compared to heavy industrial sectors such as automotive or aeronautics, and they are still not able to take full advantage of the fourth industrial revolution. With Industry 4.0, rigid planning and production processes can be revolutionized. However, the computerization of manufacturing has a high degree of complexity and its implementation tends to be expensive, which goes against the reality of SMEs that power the traditional sectors.

The purpose of this paper is to collect and discuss research results that facilitate the implementation of Industry 4.0 to the traditional sectors of textile, clothing, footwear, toys and furniture. To achieve this goal, we investigate the current state-of-the-art of the following technology enablers, where indicative works and paradigms are identified and discussed:

- 3D Printing: Additive manufacturing

- Product customization

- Interoperability

- Distributed manufacturing

- Artificial intelligence for design \& manufacturing

- Collaborative robots, complex robotic cells, interconnection and security issues

- Design and implementation of CAD/CAE/CAM algorithms and applications for the Cloud

- Efficient computation for CAD/CAE/CAM algorithms using multicore platforms.

Providing an extensive review of all the above topics is not in the scope of the present work. Additionally, the reader interested on a general overview of Industry 4.0 advancements is referred to the recent works of (Oztemel \& Gursev, 2020) or (Muhuri et al., 2019).

The remaining introduction presents the methodology used for the review. Sections 2 to 9 describe the focused review of the selected topics, with a discussion of the corresponding research questions and the related contributions. Section 10 summarizes the review with a discussion on the current status of SMEs with respect to Industry 4 and by ordering the enabling technologies in terms of their current degree of maturity and their future prospects. Finally, Section 11 contains the main conclusions of the current paper.

\subsection{Methodology}

To carry out this review, a methodology based on Systematic Literature Review (SLR) has been followed. Our research reveals that there is a significant interest in all the aforementioned areas, which is confirmed by the increasing number of scholar papers during the last years. More than 150 research papers have been reviewed and several open problems for future research are highlighted in the following sections of this paper.

\subsubsection{Justification}

Although there is an abundance of literature on Industry 4.0, no systematic literature review or mapping has been found that meets the criteria of focusing on enablers in traditional sectors. As a first step, a search has been done on Scopus, with the query "industry 4.0 AND traditional AND manufacturing AND review". The result is 24 publications that contain these terms, but only 10 are reviews, roadmaps, analysis or mappings. The work (T. Zheng et al., 2019) presents an interesting state-of-art of industry 4.0 paradigm applied in the 
manufacturing context, but not focused on traditional sectors. Ghobakhloo (2018) proposes a strategic roadmap that can serve manufacturers as a simple guide for the process of Industry 4.0 transition, but again direct references to traditional sectors are not included. There are several studies that provide a general overview and/or particular aspects or technologies concerning Industry 4.0 (Alcácer \& Cruz-Machado, 2019; Muhuri et al., 2019; Oztemel \& Gursev, 2020; Pozzi \& Strozzi, 2018). However, none of them is focusing on the industrial sectors mentioned in this paper.

In short, no analysis has been found that meets the three requirements: to deal with enabling technologies for Industry 4.0, to be focused on solutions for traditional sectors and to be systematic. This justifies the relevance of a study such as the one presented here.

\subsubsection{Research questions}

The objective of the research questions is to determine what aspects and areas related to the eight enabling technologies of Industry 4.0 in the traditional sectors have been addressed by the research community. The research questions proposed in this paper are:

1. How 3D Printing or Additive manufacturing facilitate the implementation of Industry 4.0 to the traditional manufacturing sectors?

2. How Product Customization facilitate the implementation of Industry 4.0 to the traditional manufacturing sectors?

3. How Interoperability facilitate the implementation of Industry 4.0 to the traditional manufacturing sectors?

4. How Distributed manufacturing facilitate the implementation of Industry 4.0 to the traditional manufacturing sectors?

5. How Artificial intelligence for design \& manufacturing facilitate the implementation of Industry 4.0 to the traditional manufacturing sectors?

6. How Collaborative robots, complex robotic cells and interconnection facilitate the implementation of Industry 4.0 to the traditional manufacturing sectors?

7. How Design and implementation of CAD/CAE/CAM algorithms and applications for the Cloud facilitate the implementation of Industry 4.0 to the traditional manufacturing sectors?

8. How Efficient computation for CAD/CAE/CAM algorithms using multicore platforms facilitate the implementation of Industry 4.0 to the traditional manufacturing sectors?

\subsubsection{Searching and filtering}

The database search was conducted mainly in the third quarter of 2019 and partially in the first quarter of 2020 . This was done by applying the query defined in the review protocol and then applying two filters.

The first filter consisted of searching the databases and applying the different restrictions defined in the protocol: years of search, areas of knowledge, type of document, language of publications and exclusion criteria. After applying this filter and eliminating duplicates, we obtained 5791 references.

The second filter was to identify which publications were in line with the objective of our research. To do this, we analyzed the title, abstract, methodology and conclusions of each of 
the 5791 documents, to identify the degree of interest for our research. Alignment with the objective was determined by identifying whether key concepts were included in the different sections of the publication. After applying the second filter, a total of 153 publications were classified as aligned with the objective of our research. The following sections analyze these papers to answer the eight aforementioned research questions.

\section{3D Printing: Additive manufacturing}

Under the name of additive manufacturing (AM), reference is made to a whole set of technologies that are capable of making virtual solid models into reality by means of a process that consists of depositing successive layers of finite-thickness material from the bottom to the top. A systematic search for literature on additive manufacturing in traditional sectors has been carried out. ¡Error! La autoreferencia al marcador no es válida. presents the queries and the global results of the search.

Table 1. Number of papers published that are related to additive manufacturing and traditional industrial sectors (source: SCOPUS)

\begin{tabular}{|c|c|c|}
\hline Keywords & Until 2014 & 2015-2019 \\
\hline \multicolumn{3}{|l|}{ (“Additive Manufacturing” OR “3D Printing”) AND } \\
\hline "Industry 4.0" & 0 & 262 \\
\hline "Traditional manufacturing" & 15 & 161 \\
\hline Footwear OR Shoe OR Fashion OR Textile & 23 & 155 \\
\hline Furniture OR Toy & 4 & 28 \\
\hline
\end{tabular}

3D Printing technology in the footwear sector was initially aimed at creating prototypes, especially footwear soles. In the work of (Davia-Aracil et al., 2016) it is shown how additive manufacturing can be used in this sector for the production of sole molds (Figure 1). One of the main handicaps of this technology is the slowness of the printing process compared to other traditional methods. However, when productions are customized this argument loses weight and flexibility becomes its main value (Jumani et al., 2016). In the case of anatomical insoles, manufactured exclusively for each client, AM is being successfully applied (Ciobanu et al., 2012; Davia-Aracil et al., 2018).

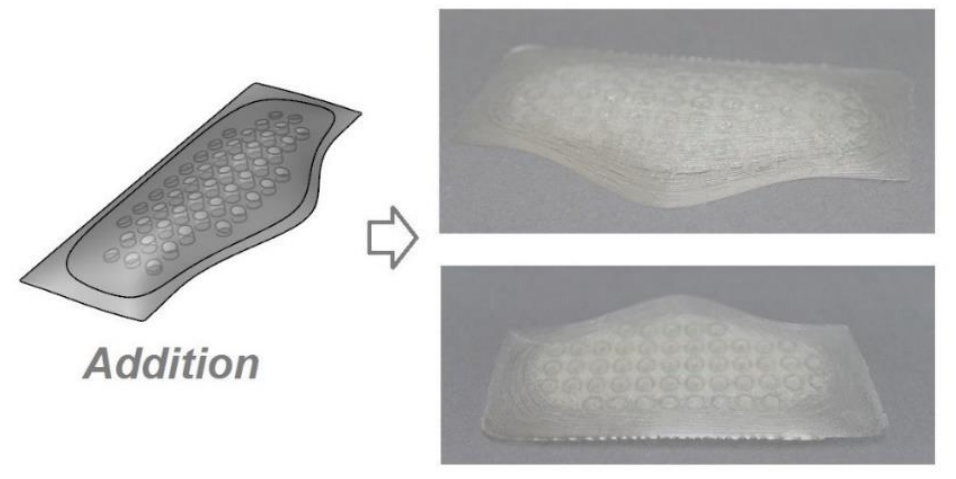

Figure 1. Insole manufactured by 3D Printing (Davia-Aracil et al., 2018)

Eventually, different software has been developed for the creation of these prototypes, initially for shoe soles, but now it is possible to prototype different kinds of footwear completely (Spahiu et al., 2016). More specifically, in fashion industry the use of 3D printing is increasing, since it presents an accelerated design process, less production time and lower costs related to inventory, storage, packaging and transport.

The furniture sector is another traditional sector where AM is being successfully applied. In the work of (Aydin, 2015) there is an assessment of its use in furniture production, i.e. how 
AM is used to produce furniture, what materials and methods are used for production and its contribution to a positive outlook on the furniture impact. Less optimistic is the work of (Kang, 2015) which ensures that the impact of 3D technology on furniture production will concentrate on the production of short and exclusive series in order to satisfy the personal preferences of the customer.

In the toy industry, the emergence of AM is twofold: on the one hand, it has favored socalled home manufacturing and a whole set of tools and models have been developed so that users can print their own toys at home with considerable savings (Petersen et al., 2017). On the other hand, new 3D printing technologies enable the production of personalized toys through the development of new and innovative 3D printing filaments. These new materials have functional characteristics such as color change, antistatic or antimicrobial properties that can be used in public places or in areas with limited access such as hospitals (LeónCabezas et al., 2017).

In summary, the unique advantages of $\mathrm{AM}$ are helping the traditional sectors to produce customized products (footwear, toys and furniture) and manufacture products with a composition of different materials that offer new/improved properties (antibacterial, biomechanical properties, etc.) However, our study shows that most of the research is focused on the realization of prototypes. There are few examples where AM is implemented within the production chain. The main limitation of AM is its low manufacturing speed, the short range of materials that can be used, the high cost of the technology, and the quality of the product. Therefore, the development of this technology in the coming years will be crucial in order to be considered a viable alternative to current manufacturing methods (Chang, 2016).

Regarding the first research question, AM has some unique advantages that can help to significantly increase industrial competitiveness by ensuring rapid adaptability to changing market needs and growing consumer demands for product customization. Although the technology cannot compete with the current one at the manufacturing level, the evolution of 3D Printing in recent years, combined with the improvement of the devices, will allow the production of not only complete prototypes, but also fully functional products that will be suitable for sale.

\section{Product customization}

Product customization emerged in the 90's as a marketing strategy closer to target demands and through which we move from mass to a more focused on consumer needs and preferences production. The concept of mass customization seeks the convergence of industrial production with product customization (Y. Wang et al., 2017; Zawadzki \&

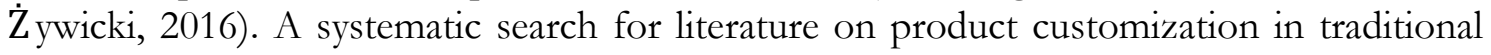
sectors has been carried out and presented in ¡Error! La autoreferencia al marcador no es válida..

Industry 4.0 connects the customer directly with the product design (Lloret-Climent et al., 2019). Footwear consumers are increasingly demanding products with new features (Shang et al., 2019) that also demand variety and renewal in market collections (Azariadis et al., 2007). The main challenge of footwear sector in Industry 4.0 falls on the personalization of the final products. The final objective is twofold: to provide consumers with a product adapted to their tastes (low-level personalization) and to provide the maximum degree of comfort to the manufactured shoe (high-level personalization) (Davia et al., 2013).

Table 2. Number of papers published that are related to product customization and traditional industrial sectors (source: SCOPUS) 


\begin{tabular}{|c|c|c|}
\hline Keywords & Until 2014 & 2015-2019 \\
\hline \multicolumn{3}{|l|}{ "Product customization" AND } \\
\hline "Industry 4.0" & 4 & 112 \\
\hline CAD & 194 & 65 \\
\hline (Footwear OR Shoe OR Fashion OR Textile) & 209 & 121 \\
\hline Furniture & 33 & 23 \\
\hline
\end{tabular}

The high-level personalization in footwear is usually related to the customer comfort. The analysis of the comfort perceived by users when wearing a given footwear has been addressed from different approaches by a large number of authors, most of them focused on the sole of the shoe (Braunstein et al., 2016; Kaplan \& Karaman, 2019; Mei et al., 2017; Papagiannis et al., 2016).

As a result of the requirements of custom design, computer models for design (CAD) and manufacturing (CAM) have been forced to adapt. Some models partially focus on the problem from the development of a size system more adapted to the biometric information of the foot (Hinojo-Pérez et al., 2016). However, most of these models focus on providing new ways to model the shoe last, by adapting to the morphology of the foot. In Azariadis (2012) a series of tools based on the finite element method (FEM) are presented to calculate realistic simulations of the foot-sole interface, in this way the biomechanical information necessary for personalization such as the internal tension and the distributions of such tension can be computed. In the footwear manufacturing process, there is a series of constraints that make these models difficult for industry to apply. In (Davia et al., 2013) a model was presented that has been verified in the industrial environment. This model establishes a set of semi-automatic tools that must be used by an expert in order to perform the correct foot-shoe last adaptation (Figure 2).

In other traditional sectors that do not require biometric adaptation (e.g., furniture or toy industry), low level personalization patterns are repeated, i.e., the search for customer taste satisfaction. In the furniture industry, recent studies focus on the new infrastructure of personalized production (Barni et al., 2018) or its control (Popescu et al., 2017). An interesting article by (Xiong et al., 2018) analyses the complete transformation process that intelligent manufacturing has brought to China's furniture industry, from infrastructure to sales, service and competitiveness. 


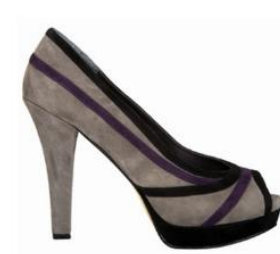

(a)

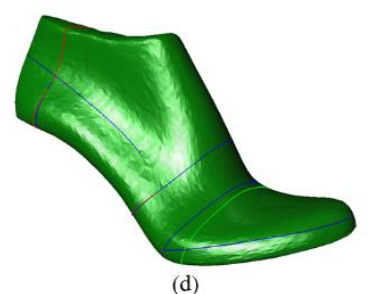

(d)

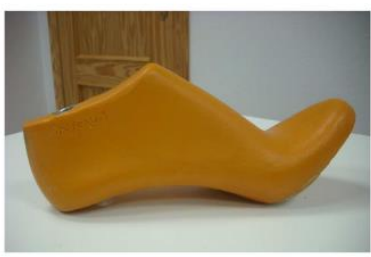

(g)

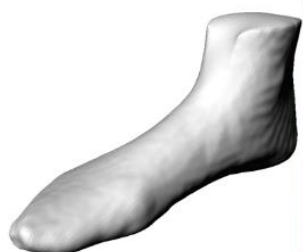

(b)

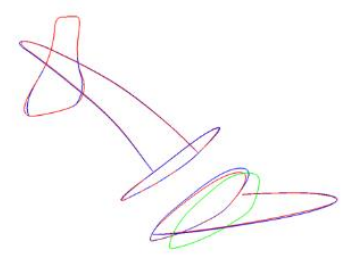

(e)

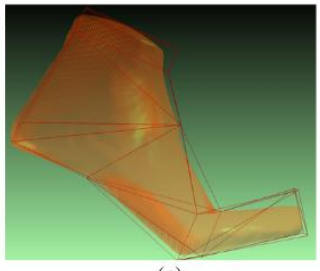

(c)

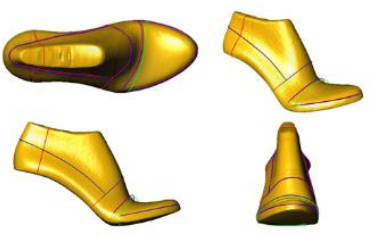

(f)

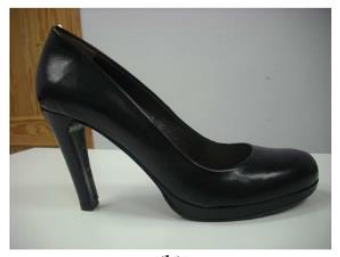

(h)

Figure 2. Custom manufacturing process (Davia et al., 2013): Woman shoe; (a) Reference shoe model, (b) Flat digitized foot, (c) Foot cage and deformation, (d) Network deformation curves and original last, (e) Network deformation curves comparative, (f) Final last model, (g) Manufactured last, (h) Final customized shoe

In summary, the footwear sector is fully aware of the concept of mass customization. Despite the advances, the main obstacle is to automatically obtain a shoe last from a digitized foot model, which is not trivial and on which no relevant advances have been found. For this reason, the most important application in the market is still focused on the low-level personalization and on the design of orthopedic footwear.

Regarding the second investigation question, companies in traditional sectors require the implementation of new business models that provide decisive advantages over the competition in the context of a market of changing needs. The mass customization model demands a high level of digitalization, from the perception of the client's needs to the design and to the automated and personalized manufacture of the product. Under this way it will represent a competitive advantage over the existing manufacturing model.

\section{Interoperability}

Industrial environments are complex ecosystems where a wide range of actors are interacting and cooperating. Interoperability is the ability of communication among Cyber-PhysicalSystems (CPS), Internet of Things (IoT) devices, factories and human via IoT, internet of services (IoS) and internet of energy (IoE) (Khan et al., 2017). It is one of the six design principles of Industry 4.0: Interoperability, Virtualization, Decentralization, Real-time Capability, Service Orientation and Modularity. The queries and the results of a systematic search for literature on interoperability in traditional sectors are presented in ¡Error! La autoreferencia al marcador no es válida..

Interoperability enables two-way industry integration: Horizontal integration between companies through value networks and vertical integration within companies through networked manufacturing systems (Mazak \& Huemer, 2015). 
Some cases of successful vertical interoperation are built on standard industrial protocols such as OPC UA (Open Platform Communications Unified Architecture) or SCADA (Supervisory Control and Data Acquisition). Unfortunately, the use of the same protocols does not imply to get this vertical interoperation since the communication may be still inconsistent and create 'vertical silos', as claimed by Robert, Kubler, Traon and Framling (Robert et al., 2016).

Table 3. Number of papers published that are related to interoperability and traditional industrial sectors (source: SCOPUS)

\begin{tabular}{|c|c|c|}
\hline Keywords & Until 2014 & 2015-2019 \\
\hline \multicolumn{3}{|l|}{ Interoperability AND } \\
\hline "Industry 4.0" & 2 & 235 \\
\hline "Traditional manufacturing" & 3 & 3 \\
\hline SME & 148 & 72 \\
\hline Footwear OR Shoe & 20 & 5 \\
\hline "CAD/CAM" & 43 & 19 \\
\hline Textile OR Clothing & 46 & 18 \\
\hline Toy & 9 & 4 \\
\hline
\end{tabular}

The case of the horizontal dynamic integration of business partners to form a value network is a more challenging open issue in the research agenda. Nevertheless, some very interesting examples of horizontal interoperation can be found, such as the standards framework introduced by Mazak and Huemer (2015). It adapts particularly well to traditional manufacturing companies since they base their work on Open-edi as reference framework to identify and integrate existing standards.

The special characteristics of traditional manufacturing sectors with regard to interoperability were already detected some time ago. Chituc, Toscano and Azevedo (2008) considered that the changing economic and technological factors have forced small and medium size enterprises to new forms of collaboration, such as Collaborative Networks (CNs). These authors review the capacity of footwear sector to achieve interoperability in a $\mathrm{CN}$.

Most industry-specific initiatives use a two-layered approach: messaging and business processes. The project SPRINTS (Shoe PRocess INTeroperability Standard) is an attempt to regulate and rationalize part of the footwear industry interorganizational communication. SPRINTS is an XML-based standard that covers most of the information transfers needed in the shoe manufacturing field, from shoe design to manufacture and describes both horizontal and vertical interoperability (Danese et al., 2011).

The eBIZ-TCF project is aimed at boosting and harmonizing e-business processes and data exchanges in the textile/clothing and footwear (TCF) industries in Europe (CEN, 2013; Ponis et al., 2012). The project was particularly concerned with promoting the uptake of electronic business standards among SMEs in these industries, proposing a reference architecture for e-business. This architecture aims to tackle the different requirements of both manufacturer-retail supply chains and manufacturer-supplier networks (horizontal interoperability).

Another example is the NIMBLE project (Deng et al., 2019). Its objective is the development of a cloud and IoT platform specifically targeted at supply chain relationships and logistics. Core capabilities enable firms to register, publish machine-readable catalogues for products and services, search for suitable supply chain partners, negotiate contracts and supply logistics, and develop private and secure information exchange channels between firms. One important part of the project enables the semantic interoperability in any sector, particularly in traditional ones.

A very recent initiative in the sector of toy industry is the ToyLabs project (Michalitsi-Psarrou et al., 2019). This project aims to build a new, collaborative value chain for product 
development in the toy industry, with business interoperability playing a key role. The methodology behind the ToyLabs platform focuses on the incorporation of cross-sectorial business process interoperability capabilities that aim to create a common vocabulary, understanding and a communication gateway for the identification of potential partners even from sectors that were previously unrelated to the toy industry and the exchange of requirements and specifications between them.

In summary, research on interoperability in traditional sectors focuses on the total integration of all business processes, including internal aspects of companies such as design and production, but also external aspects such as the supply chain, distribution, logistics or contract negotiation. The challenge for the coming years is to make the entire production system interoperable with security, by defining common vocabularies, based on Cloud Computing and the generalization across all traditional sectors.

Regarding the third research question, ensuring the interoperability of systems and processes is the sine qua non basis for the development of Industry 4.0. It is not possible to make use of the other enabling technologies if the interoperability of systems with security and safety has not been resolved before.

\section{Distributed manufacturing}

Distributed manufacturing can be defined as a form of decentralized manufacturing using a network of geographically dispersed manufacturing facilities that are coordinated using information technology (Vasseur, 2017). ¡Error! La autoreferencia al marcador no es válida. presents the queries and the global results of the systematic search. Note that the terms "flexible manufacturing" and "mini-factory" have been added to the query, since they are closely related to that of "distributed manufacturing".

Traditional manufacturing companies, such as those specialized in clothing and footwear, must determine methods to improve supply chain management. For instance, Guo et al., (2015) focus on the production monitoring and scheduling problem faced by this type of distributed companies. An intelligent decision support system architecture is developed in which RFID and cloud technologies are integrated for real-time production capture and remote production monitoring, whereas intelligent optimization techniques are applied to generate effective production scheduling solutions.

Table 4. Number of papers published that are related to distributed manufacturing and traditional industrial sectors (source: SCOPUS)

\begin{tabular}{|c|c|c|}
\hline Keywords & Until 2014 & 2015-2019 \\
\hline \multicolumn{3}{|l|}{$\begin{array}{l}\text { ("Distributed manufacturing” OR "Flexible manufacturing” OR "Mini- } \\
\text { factory") AND }\end{array}$} \\
\hline "Industry $4.0 "$ & 1 & 123 \\
\hline "Traditional manufacturing" & 44 & 15 \\
\hline Footwear OR Shoe & 19 & 7 \\
\hline Textile OR Clothing & 80 & 7 \\
\hline Furniture & 22 & 6 \\
\hline
\end{tabular}

Rauch, Unterhofer and Dallasega (2018) consider additive manufacturing as one of the emerging technologies for ensuring the development of distributed manufacturing systems, especially for manufacture in traditional labor-intensive sectors based on handcrafted manufacturing processes. 

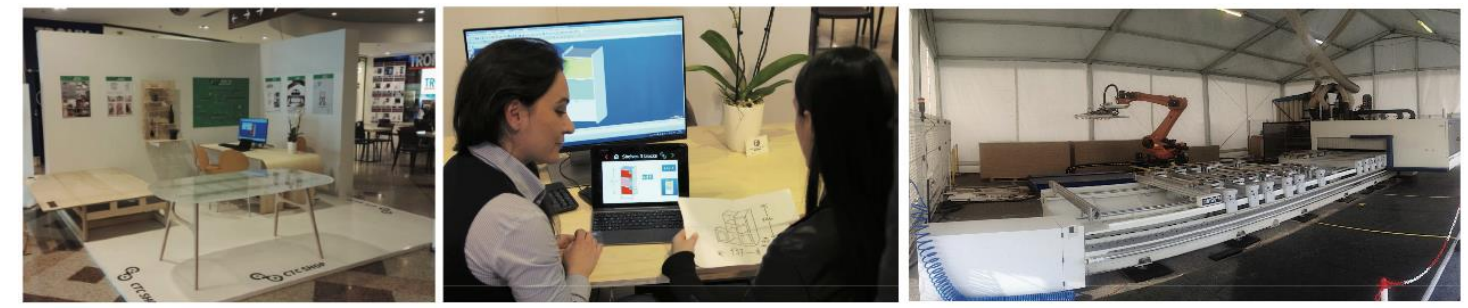

Figure 3. СTC: From left, the CTC shop, a customer working on cabinet configuration, and the CTC working center (Barni et al., 2017)

Distributed manufacturing and circular economy are terms that are usually linked. Moreno et al., (2016) consider that the transformational shift from centralized to decentralized (usually smaller-scale) manufacturing, powered by digital technologies must go hand in hand with circular economy. One example is the Shoe Lab project, a proof of concept that demonstrates the circular economy in the field of sports shoes. This project identifies and evaluates the opportunities that digital technologies offers to disrupt traditional industry models when combined with big data.

Barni et al., (2017) propose a new business model, "Close To Customer" (CTC), relying on the concept of mini-factory as a production system able to move the manufacturing industry within urban environments, creating sensible added value in the furniture industry. The basic idea of CTC is designing, producing and selling the goods directly in the shopping mall. In practical terms, the client customizes the furniture using a user-friendly configurator with the support of a trained operator. Once the furniture project is finalized an order is generated and sent to the CTC mini factory, where the manufacturing process is performed. Once manufactured, the products are ready to be collected by local couriers for fast delivery to the customer (Figure 3).

In short, the latest trends in distributed manufacturing focus on finding standards for integration and leveraging existing technologies such as RFID or Cloud Computing. The main challenges ahead are to get full distribution of production in traditional sectors, which will not be achieved without more automated, safer and more sustainable processes. Several opportunities are identified: personalization, sustainability, disruptive business models and local economy multiplier effects.

Regarding the fourth research question, the distribution of production allows for proximity to the consumer, greater sustainability and the possibility of personalization, all of which are fundamental characteristics in smart manufacturing and Industry 4.0.

\section{Artificial intelligence for design \& manufacturing}

The application of Artificial Intelligence (AI) in design and manufacturing is an active field of research during the last decades. Computational intelligent techniques such artificial neural networks, fuzzy logic, genetic algorithms have been used for the design and manufacturing of products in traditional sectors. ¡Error! La autoreferencia al marcador no es válida. presents the results of a literature search in the context of AI in traditional manufacturing sectors.

Table 5. Number of papers published that are related to Al and traditional industrial sectors (source: SCOPUS)

\begin{tabular}{|c|c|c|}
\hline \multirow{2}{*}{\multicolumn{3}{|c|}{$\begin{array}{l}\text { Keywords } \\
\text { "Artificial Intelligence" AND (Design OR Manufacture) AND }\end{array}$}} \\
\hline & & \\
\hline Furniture & 47 & 65 \\
\hline Footwear OR shoe & 55 & 47 \\
\hline Apparel OR Cloth OR Garment OR Fashion & 264 & 161 \\
\hline
\end{tabular}


According to Luce, (2018) there is a rich and expansive space of AI and fashion. Neural networks, generative adversarial networks (GAN), data mining are some of the techniques among others that are used in natural language processing, computer vision, predictive analytics and robotics for shopping and product discovery, sales, designing, and the supply chain in fashion.

Xu et al., (2018) apply AI in modern fashion industry to solve intractable decision-making problems in all phases of the manufacturing process and in shorter time than traditional mathematical methods. Computational intelligence techniques have been applied in cutting, sewing, finishing and packing of garments (Koustoumpardis \& Aspragathos, 2014; Triantafyllou et al., 2011).

A method for automatic fashion product design and development using AI was presented in Yan et al. (2018). The proposed method was applied to a 3D-to-2D garment design case. A perception-based pattern-modification model based on fuzzy logic is developed, where patterns (Figure 4) can be automatically modified (Hong et al., 2018).

A method based on 3D virtual-reality technology is used to simulate human activities and to measure clothing pressures by determining key elements of the wearing comfort is introduced in (Liu et al., 2018). A machine learning model based on Naïve Bayes classifier is used to predict garment fit as it shown in Figure 5.

GAN are used widely in fashion and decoration (Liu et al., 2018; Meng et al., 2018; Zhao \& $\mathrm{Ma}, 2018)$. An attribute GAN to generate clothing-match pairs is proposed by Liu et al., (2019). A method for conceptual fashion design using augmented reality and conditional GAN models is presented in Zhao \& Ma, (2018). An expert system for the fabrics selection to design transformable clothing based on user's level of quality is developed in Zakharkevich et al. (2018).

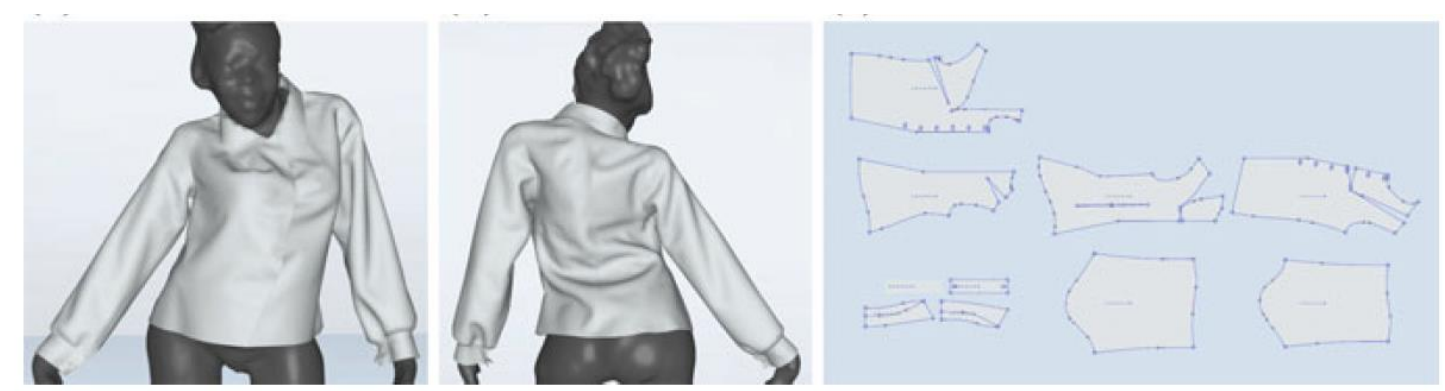

Figure 4. Automated pattern generation following modifications in garment design (Hong et al., 2018)

(a)

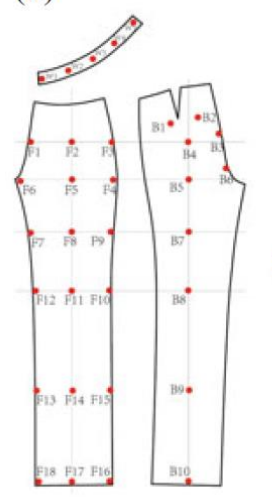

(b)

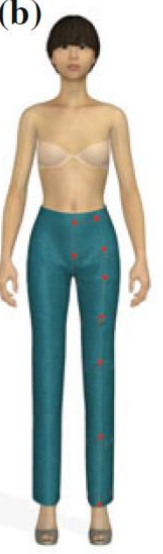

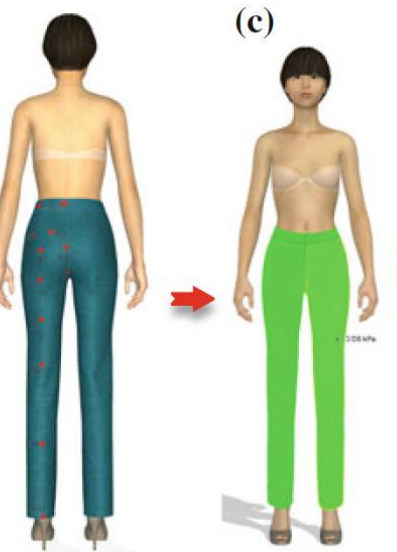

(c)

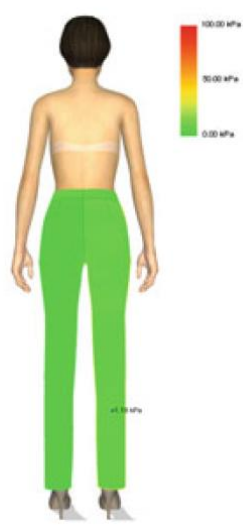


Figure 5. Digital clothing pressure measurement by virtual try-on (K. Liu et al., 2018)

In the area of footwear industry, artificial neural networks (ANN) are used to develop a system for shoe lasts selection with mild diabetes (Wang et al., 2019) and for the estimation of the maximum pressure over the foot plantar surface exerted by a two-layer shoe sole for three distinct phases of the gait cycle (Xidias et al., 2015). Automated foot model reconstruction is accomplished through the use of the self-organizing Growing Neural Gas network (Jimeno-Morenilla et al., 2016).

In the furniture sector, ANNs are used to ergonomically design furniture (Agha \& Alnahhal, 2012; Bhuiyan \& Hossain, 2015). Multi-objective machine scheduling in the custom furniture industry based on evolutionary approach together with a ANN is presented in (Vidal et al., 2011). A hybrid simulated annealing method was used to solve the two-stage assembly of bedroom furniture problem with multiple non-identical assembly machines in (Navaei et al., 2013).

Regarding the fifth research question, it is anticipated that more research efforts on the development of new AI tools for designing and evaluating concepts or products will be realized during the next years towards modernization of SMEs in the traditional manufacturing sectors. These tools will alleviate the knowledge uncertainty/fuzziness by handling huge amount of data during the early phases of design, providing more customized, rapidly manufactured, products.

\section{Collaborative robots, complex robotic cells, interconnection and safety issues}

While traditional manufacturing sectors are producing highly customized products, robotic tasks (e.g., assembly) are becoming more challenging. Current challenges of shorter product life-cycles and highly customized products are addressed by Industry 4.0. The new manufacturing paradigm consists in modular factory structures composed of smart devices within a networked IoT environment (Román-Ibáñez et al., 2018).

In traditional manufacturing sectors, robots are used mainly for assembly tasks. Systems for the autonomous or collaborative assembly of furniture sets and sewing of garments using robots, robotic monitoring systems in footwear industry as well as unfolding of garments are presented. Scalability, safety and security issues are addressed in the development of these systems.

¡Error! La autoreferencia al marcador no es válida., presents the results of the literature search in the context of robot applications in traditional manufacturing sectors. The number of papers in the last five years shows that there is a significant research effort towards the modernization of these sectors.

Table 6. Number of papers published that are related to robotics and traditional industrial sectors (source: SCOPUS)

\begin{tabular}{|c|c|c|c|c|}
\hline Keywords & & Until 2014 & \multicolumn{2}{|c|}{ 2015-2019 } \\
\hline \multicolumn{5}{|l|}{ Robot AND } \\
\hline & Furniture & & 201 & 115 \\
\hline & Footwear OR shoe & & 154 & 92 \\
\hline & Apparel OR Cloth OR Garment & & 318 & 168 \\
\hline
\end{tabular}

A risk assessment to handle the hazards imposed on collaborative robot applications and safety issues for Human-Robot Collaboration (HRC) is presented in Hull \& Minarcin (2016). Systems for the autonomous assembly of furniture sets (e.g., tables, chairs) using multiple robots are presented in (P. Huang et al., 2018; Knepper et al., 2013; Suárez-Ruiz et al., 2018). 
A planning and assembly system for furniture pieces is introduced, where KUKA robots perform geometric and symbolic planning, assume different roles, and coordinate actions to complete the assembly of a table. For objects that are too large or heavy to be manipulated by one robot, a set of robots is coordinated to complete the task (Knepper et al., 2013). A method for the automation of the assembly of furniture sets using robots is presented in (P. Huang et al., 2018), where a system that incorporates basic operation skills in mechanical assembly using machine learning is developed. CAD-based motion planning with reinforcement learning, for contact-rich manipulation problems is developed in (Thomas et al., 2018).

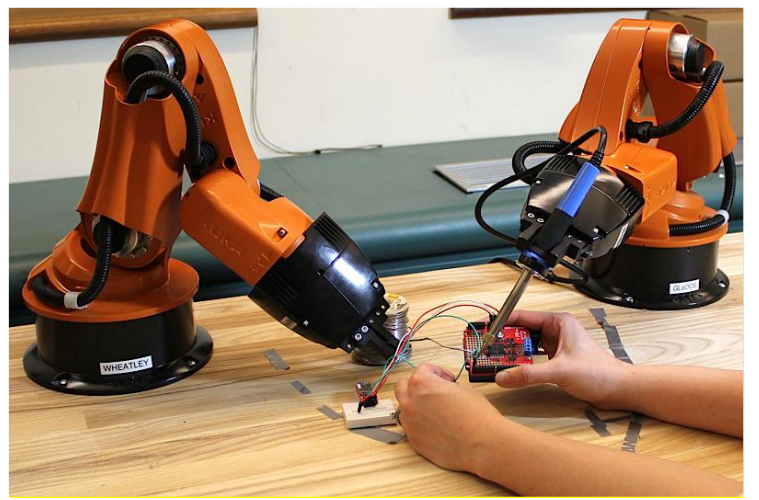

Figure 6. Shared workspace of human-robot collaboration (Hayes \& Scassellati, 2014)

A framework for expert design, customization and robot fabrication using standard power tools for furniture and custom carpentry structures is developed by Lipton et al. (2018). KUKA robots are responsible for the cutting process, while humans assemble the final product guided by an interactive interface. Furniture set assembly is used to develop a model set for HRC (Zeylikman et al., 2018). A library of 3D models is developed taking into account the modularity and scalability of components of furniture sets. Human multimodal cues for furniture assembly where analyzed in order to find the most informative so as to enhance the communicational and social skill of collaborative robots (Kontogiorgos et al., 2018).

A low-cost monitoring system based on robotic arm cells (Figure 7) focused on Industry 4.0 footwear factories is developed in (Román-Ibáñez et al., 2018). An enhanced 3D monitoring client, using the wired and/or wireless network was used for robotic simulation and cell design software for system cost minimization. Scalability, safety and security were key factors in the development of the monitoring system with existing encryption algorithms applied to data streams (Román-Ibáñez et al., 2018).
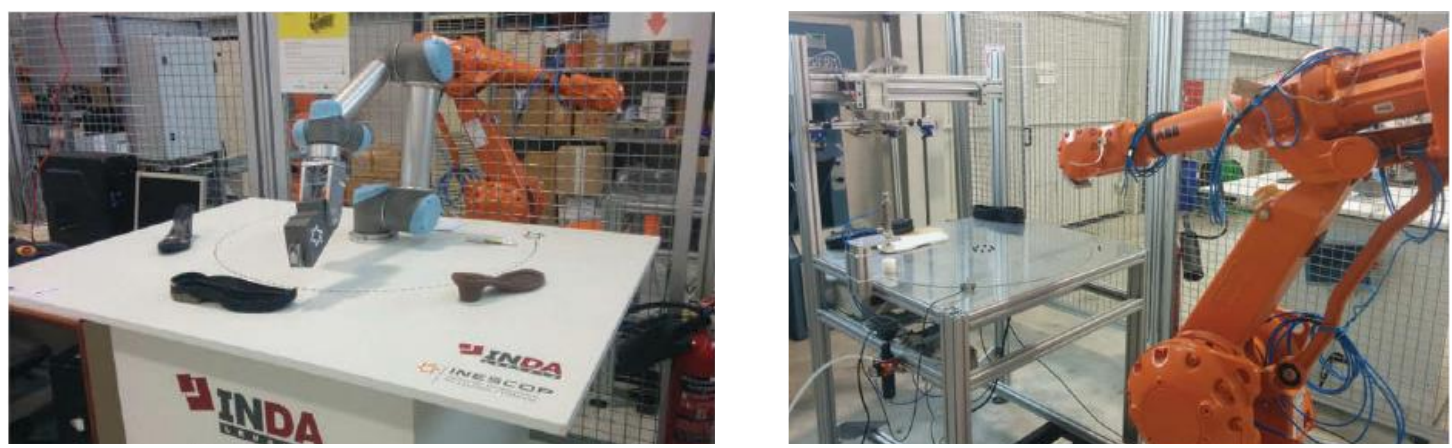

Figure 7. (left) Offline adhesive spray of shoe soles. (right) Shoe sole application with laser scanner (Román-lbáñez et al., 2018)

Several works have been presented towards the automation of tasks in the apparel industry, e.g., sewing of fabrics, unfolding, etc. Sewing of double ply fabrics (Figure 8) using a robot and a conventional industrial sewing machine using fuzzy logic and neural networks are 
presented in (Koustoumpardis \& Aspragathos, 2014; Triantafyllou et al., 2011). Robotized unfolding of garments using depth sensors, is presented in (Triantafyllou \& Aspragathos, 2018).

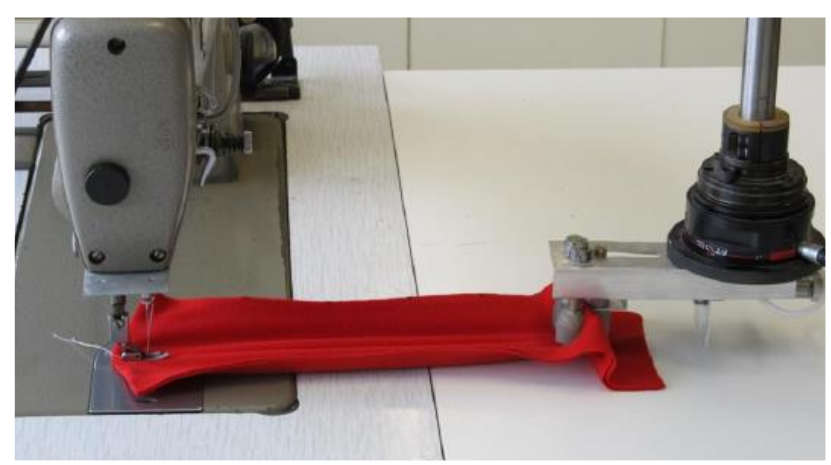

Figure 8. A robotized sewing machine (Koustoumpardis \& Aspragathos, 2014)

Nowadays, the research and development efforts on collaborative robots are very intense. Concerning the sixth research question, collaborative robots are important components of flexible manufacturing systems that will face the challenges for shorter product life-cycles and highly customized products made by SMEs in traditional manufacturing sectors. New low-cost, collaborative robots with advanced levels of cognitive and communication skills appear that can be used to facilitate the manufacture of traditional products in the Industry 4.0.

\section{Design and implementation of CAD/CAE/CAM algorithms and applications for the Cloud}

Under the "everything-as-a-service" concept of cloud computing platforms (Pallis, 2010), the cloud-based CAx model benefits from the Software as a Service (SaaS) module, where the applications run entirely on a server. A user can access these applications remotely through a thin client interface that serves for input and output operations (Zissis et al., 2017). The collaborators can be designers, engineers, manufactures, marketing personnel, and endusers in distributed locations. SMEs in traditional manufacturing sectors with limited human or financial resources and lack of personnel with technical skills can benefit from cloud computing technological innovations. Table 7 presents the results of a systematic literature search in the context of cloud computing in traditional sectors.

Table 7. Literature search results on cloud computing and traditional industrial sectors (source: SCOPUS)

\begin{tabular}{|c|c|c|}
\hline Keywords & Until 2014 & 2015-2019 \\
\hline \multicolumn{3}{|l|}{ "Cloud Computing" AND } \\
\hline CAD OR CAE OR CAM & $19 / 6 / 1$ & $22 / 8 / 9$ \\
\hline "CAD/CAE/CAM" & 11 & 13 \\
\hline (Footwear OR Shoe) & 5 & 17 \\
\hline (Footwear OR Shoe) AND (CAD OR CAE) & - & $7 / 2$ \\
\hline (Textile OR Garment) & 15 & 36 \\
\hline (Textile OR Garment) AND (CAD OR CAE) & 2 & $3 / 2$ \\
\hline Toys & & 5 \\
\hline (Other industry sectors) AND (CAD OR CAE) & & $6 / 7$ \\
\hline \multicolumn{3}{|l|}{ "Cloud Manufacturing" AND } \\
\hline Footwear & 1 & 4 \\
\hline (Textile OR Garment) & 8 & 16 \\
\hline Toys & 2 & 2 \\
\hline
\end{tabular}

According to Table 7, Cloud Manufacturing plays a dominant role for the implementation of Industry 4.0 practices by SMEs in traditional sectors. The "Design Anywhere, 
Manufacture Anywhere" philosophy aims to transform manufacturing industry from production-oriented to service-oriented (Zhang et al., 2014). SMEs in the traditional sectors, like footwear, textile, and toys, seem to follow with a slower pace during the last five years.
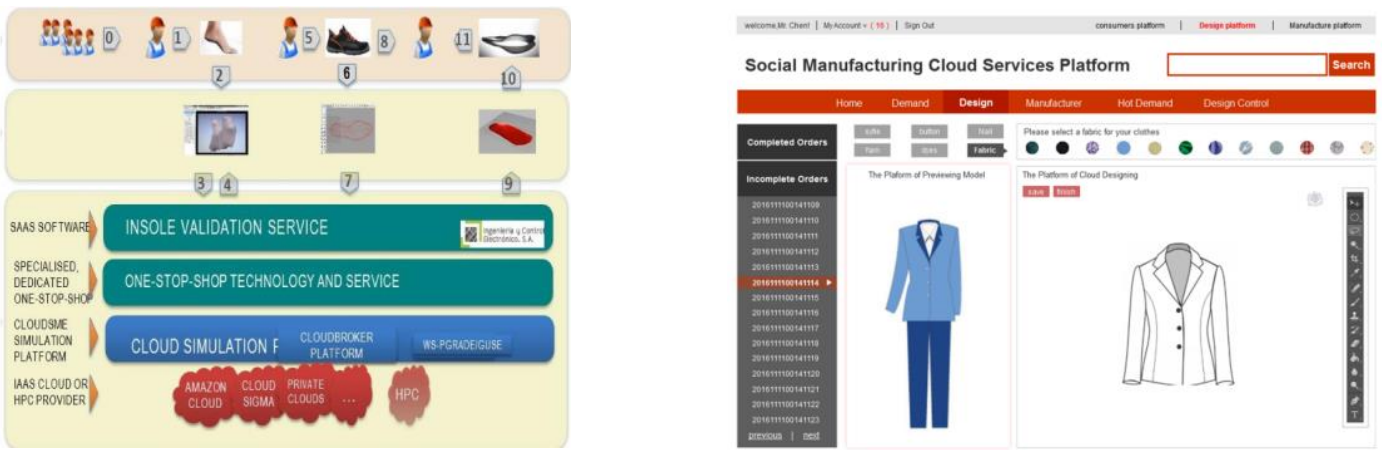

Figure 9. (left) A user scenario of customized insole design (Terstyanszky et al., 2016). (right) The cloudbased interface of the end-user for cloth customization (Shang et al., 2018).

Several recent works focus on the design of customized shoe insoles, mainly for healthcare purposes (Azariadis et al., 2018; Mandolini et al., 2017; Terstyanszky et al., 2016; Zissis et al., 2017). The transition of design, engineering and simulation operations to the cloud, enabled the creation of insoles on a single platform (Figure 9-left). Textile industry benefits from cloud-based CAx platforms mainly in the domain of smart cloths and cloth customization (Figure 9-right)(Shang et al., 2018). Smart cloths are embedded with fabric sensors, circuits and electrodes and find a variety of applications from healthcare (Chen et al., 2016; Hu et al., 2018) to replication detection and styling advices (Kumar Reddy \& Rajeshwari, 2016) (Figure 10). SMEs in traditional industries exploit the cloud infrastructure by planning and controlling the production line, mass customization, shop scheduling, material planning, and improvement of production efficiency; see (J. Liu et al., 2019; Mourtzis et al., 2015; Shang et al., 2018; Udayangani et al., 2019) and references therein.
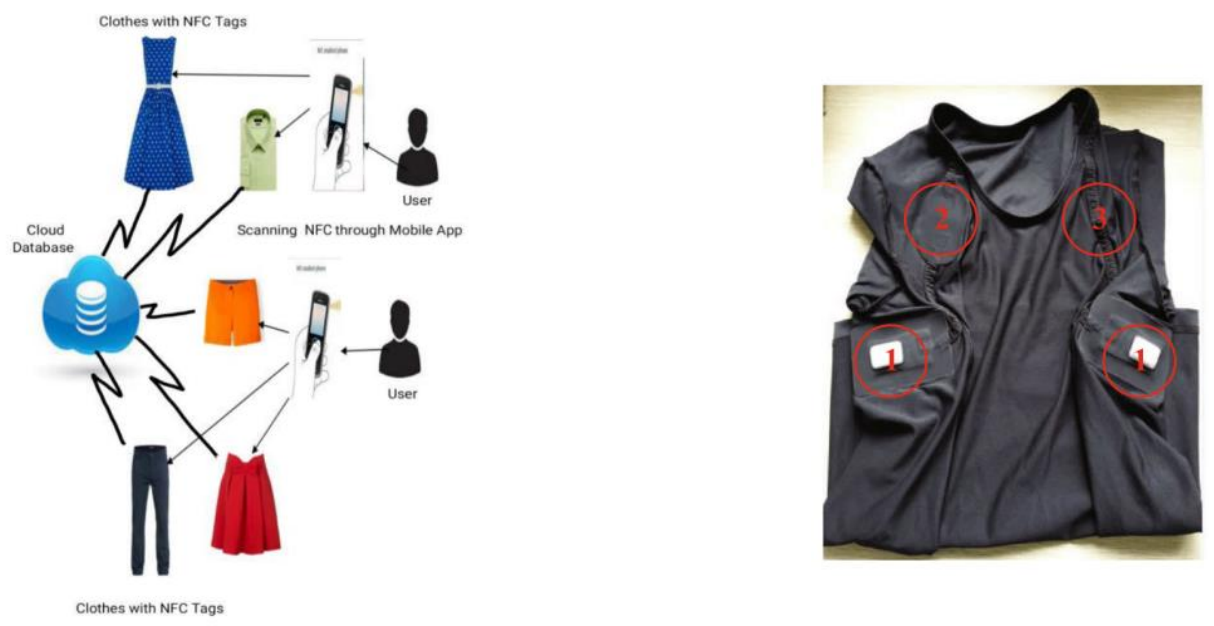

Figure 10. (left) The 'Interactive Cloths' System (Kumar Reddy \& Rajeshwari, 2016) provides styling advices to users and informs manufacturing company for any replicas. (right) The smart cloth of (Chen et al., 2016) includes micro sensors employed for measurement of various physiological indicators of human body.

Regarding the seventh research question, cloud infrastructure upgrades small/medium enterprise model to an extended business model that includes IT technologies and smart services without the expense of an in-house acquisition (Abdollahzadegan et al., 2013; Zheng 
et al., 2017). Cloud-based CAx environments provide SMEs with "on-demand" and "independent of device and location" tools for an online company/customer collaboration, real-time design, instant access to engineering and manufacturing technical and software solutions, unlimited data storage, and flexible production planning. The easy access of cloud computing platforms together with personnel training, national/international funding schemas, and SMEs business model reorganization can reinforce the competency of cloudbased CAx adaptation.

\section{Efficient computation for CAD/CAE/CAM algorithms using multicore platforms.}

The importance of multi-core GPUs and parallel computing for the implementation of Industry 4.0, lies on the development of efficient software tools that can upgrade the performance, on the cloud or the web, of CAx applications that involve intensive computation tasks. Real-time co-design with 3D model visualization and rendering, computation algorithms for solid models, real-time engineering simulation and analysis, (distributed) additive manufacturing operations, collision detection, and data exchange among different parties, are only few examples of CAx-based computationally expensive algorithms that are employed by SMEs in traditional sectors. Literature search results that associate traditional manufacturing sectors with applications employing a multi-core GPU infrastructure are presented in Table 8.

Table 8 depicts extensive research on multi-core GPUs and parallel computing for CAx applications. In the footwear industry, multiple CPU processors are mainly employed for applications related to the design, simulation and analysis of therapeutic footwear, insoles and shoe lasts. Morell-Gimenez et al., (2013) propose an optimisation method for last production that uses multi-core GPUs to improve the tool-path computation and reduce the average machining time (Figure 11).

Table 8. Literature search results on multicore GPUs/CPUs in traditional manufacturing sectors (source: SCOPUS)

\begin{tabular}{|c|c|c|}
\hline Keywords & Until 2014 & 2015-2019 \\
\hline \multicolumn{3}{|l|}{ ("Multicore Processor" OR Multiprocesor OR GPU) AND } \\
\hline (CAD OR CAE OR CAM) & $29 / 28 / 18$ & $31 / 16 / 18$ \\
\hline Footwear & 7 & 2 \\
\hline Textile & 6 & 6 \\
\hline \multicolumn{3}{|l|}{ "Parallel Computing" AND } \\
\hline (CAD OR CAE OR FEM OR CAM) & $190 / 34 / 188 / 210$ & $82 / 16 / 87 / 121$ \\
\hline Footwear & 12 & - \\
\hline (Textile OR cloth) & 18 & 20 \\
\hline
\end{tabular}

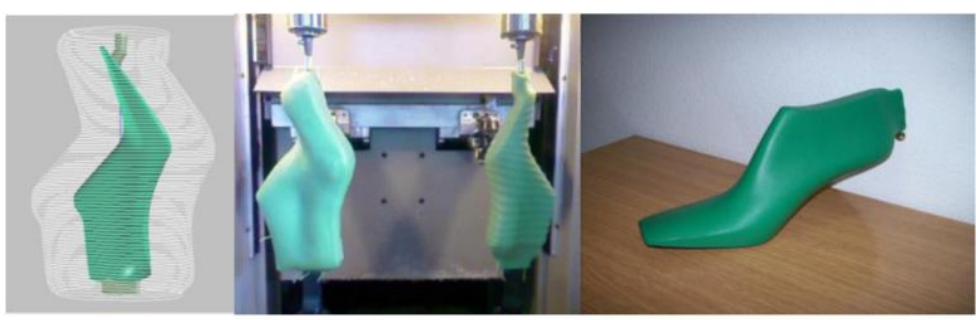

Figure 11. Shoe last machining according to (Morell-Giménez et al., 2013). 
In the textile industry distinctive works show that multicore CPU/GPU architectures and parallel computing are mainly employed for tasks like (virtual try-on) cloth simulation, clothcloth collision detection (Tang et al., 2013; Vassilev, 2016), cloth animation (Xue et al., 2017; Zang et al., 2018), authoring and simulating of cloth or garment patterns (Leaf et al., 2018); see (Figure 12).
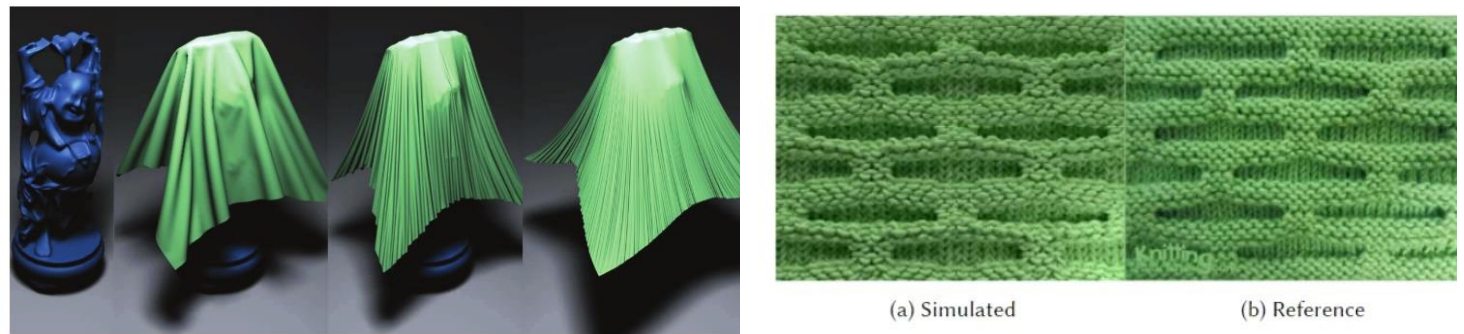

Figure 12. (left) Cloth simulation results using varying resolutions (Tang et al., 2013). (right) Simulation results of yarn-level patterns (Leaf et al., 2018).

In the manufacturing sector, parallel algorithms are employed for tasks like dynamic production planning and cycle time forecasting (Nakamura et al., 2017; Tan et al., 2020; J. Wang et al., 2018), or evaluation and ranking of alternative technologies on the basis of economic and technological criteria (Solgi et al., 2019). The main focus, though, of current research lies on the evolving technology of additive manufacturing. Employing a parallelized genetic algorithm that is implemented on GPU, Li et al. (2019) find the best model orientation that minimizes the building time and supporting area. The genetic algorithm of R. Huang et al. (2018) that is based on CUDA, achieves an optimum part deposition orientation (Figure 13) and the desired surface quality in a reduced by $94.8 \%$ running time compared with the traditional genetic algorithms.

Regarding the eighth research question, multi-core GPUs and parallel computing can directly enhance the software infrastructure of Industry 4.0 technologies that are employed by SMEs in traditional sectors. A fast and more efficient performance of computationally expensive tasks enable SMEs to overcome the delays related to software tools and allows personnel to focus on more productive tasks.
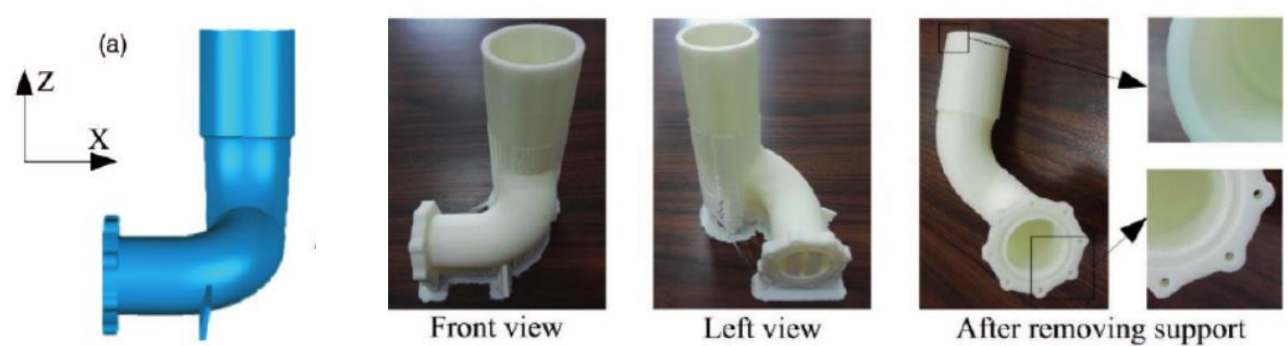

Figure 13. The optimum position results in a produced object with minimum support material ( $R$.

Huang et al., 2018).

\section{Traditional SMEs in the Industry 4.0 era}

Research works on the status of SMEs (Doyle \& Cosgrove, 2019; Villa \& Taurino, 2019) shows that the business profile of SMEs does not allow them to easily expand or deliver innovative products so as to stay competitive. Their organizational structure and technological infrastructure that includes different manufacturing capacities, a tight job market, in-house designs and an in-house production team, time-consuming daily operations, 
a limited control on the orders priority and estimation time, in addition to the "one-man" technical knowledge model and their limited financial resources, are not a supportive environment to explore new technologies and realize new pioneer designs (Daxhammer et al., 2019).

The recent funding calls of European Commission under the umbrella of Horizon 2020 reveal the need for a strategic next-generation platform building. Calls like "Digitising European Industry (DEI)" (2018-2020) that support public-private partnership for advanced manufacturing research and innovation, "Digitising and transforming European industry and services (DT-ICT-09-2020)", "ICT Innovation for Manufacturing SMEs (I4MS)" and "PanEuropean advanced manufacturing assistance and training for SMEs (INNOSUP-08-2020)" demonstrate that the digital transformation of SMEs in the Industry 4.0 era is an open issue of major importance for the global economy.

According to Oztemel \& Gursev, (2020), for the implementation of Industry 4.0, SMEs of traditional industry sectors have to apply new business models. One step towards SMEs technological evolution is the training of the management level and shop-floor employees to understand technologies and related to Industry 4.0 topics so as to assess a target-oriented development of the enterprise (Wienbruch et al., 2018). Industry 4.0 implementation is efficiently supported by an upgrade to the physical and IT infrastructure of SMEs with new smart technical equipment, reliable industrial infrastructure and networked machines (Villa \& Taurino, 2019). The new service-oriented technological infrastructure requires for SMEs to reorganize their structure and management strategy so to efficiently manage distributed resources (human and equipment) that remotely interact together.

The evolution of SMEs towards Industry 4.0 should be seen as an ongoing development project, where the eight technological enablers that are discussed in this paper, can efficiently support in multiple cost-effective manners. SMEs can benefit from these enablers in many ways such as, the easy incorporation of new products, efficient management of scheduled works and priorities, accurate performance of job scheduling tasks, control of manufacturing logistics and productivity, decentralization and interconnection of each machine with all the production process, machine state remote visualization, organization and management of the warehouse, collection of real time data concerning energy, performance and production information, real time processing and reactions etc.

Table 9: Classification of the eight enablers according to their current maturity degree and their prospects.

\begin{tabular}{|c|c|c|c|}
\hline \multicolumn{2}{|r|}{ Current trends } & \multicolumn{2}{|r|}{ Challenges } \\
\hline Mature & $\begin{array}{l}\text { Interoperability } \\
\text { Multi-core GPUs and Parallel } \\
\text { computing }\end{array}$ & $\begin{array}{l}\text { Very } \\
\text { relevant }\end{array}$ & $\begin{array}{l}\text { Distributed Manufacturing } \\
\text { Product customization } \\
\text { Cloud Computing } \\
\text { Collaborative robotics }\end{array}$ \\
\hline In progress & $\begin{array}{l}\text { 3D Printing } \\
\text { CAD/CAE/CAM in cloud } \\
\text { Collaborative robotics }\end{array}$ & Relevant & $\begin{array}{l}\text { Interoperability } \\
\text { 3D Printing } \\
\text { Multi-core GPUs and Parallel } \\
\text { computing } \\
\text { AI in Design }\end{array}$ \\
\hline Incipient & $\begin{array}{l}\text { Distributed Manufacturing } \\
\text { Product customization } \\
\text { AI in Design }\end{array}$ & $\begin{array}{l}\text { Not very } \\
\text { relevant }\end{array}$ & \\
\hline
\end{tabular}

On the basis of the literature review and the above discussion, we organize and order the aforementioned enabling technologies in terms of their current degree of maturity and their future prospects (jError! No se encuentra el origen de la referencia.). In terms of the 
current degree of maturity, we divide the technologies into "mature", "in process", and "incipient". As for their degree of importance that is expected in the future, we classify them to "very relevant", "relevant" and "not very relevant".

Our literature review showed that the competence of SMEs to follow the Industry 4.0 model is still an open issue. SMEs in traditional industry sectors may reveal a similar economic and business background, but each sector has its own singularities. Individual technical analysis of each enterprise's status and objectives, together with a guiding business model framework that focuses on specific development processes, can facilitate the transition of SMEs to the digital era of Industry 4.0.

\section{Conclusions}

The systematic review of the eight technology enablers in traditional manufacturing sectors revealed that some of these technologies are very mature (e.g., parallel computing) but others require a lot of effort to be developed and adopted (e.g., AI in Design).

Three-dimensional printing technology is already penetrating different traditional sectors with different degrees of depth. Our analysis shows that the possibilities offered by this technology are not yet complete and its capacity for innovation continues to grow.

Interoperability enables two-way industry integration: Horizontal integration through value networks and vertical integration in networked manufacturing systems. There is still further research needed to provide mechanisms to enable information to flow. There is still a lack in the harmonization of terms, concepts and standards for inter- and cross-industry communication.

There are important challenges that affect distributed manufacturing to become an efficient and effective reality in the traditional manufacturing companies such as: personalization model, technology maturity, unsolved standards, compatibility, regulation, certification assurance of quality, data sharing, governance, security and the new types of ownership and property protection.

Collaborative robots are important components of flexible manufacturing systems in traditional manufacturing sectors in order to face the challenges for shorter product lifecycles and highly customized products. The synergistic combination between humans' dexterity and robots' precision and payload advances, increases the overall efficiency of the system. This is achieved by advanced levels of cognitive and communication skills in order to collaborate in a safe manner.

New methods in systems design, perception and human robot interaction are expected in the near future. Advanced action, interpretive, envisioning, learning and reasoning abilities in combination with advanced perception, interaction and decisional autonomy will allow robots to identify various parameters in dynamic environments, acquire knowledge, interpret and act autonomously or interact safely with humans. Immersive virtual reality will allow a more natural and realistic way to inspect and monitor robotic cells, while advances in Human-Robot Collaboration approaches will allow and/or simplify the deployment of advanced assembly systems in the traditional industry.

The rapid evolution of web-oriented technology enabled cloud-computing to be used as a collaboration platform. The progress in information technologies together with the deployment of IT resources can efficiently support an online, fast collaboration, and ondemand access to shared data with high reliability, scalability and availability in a distributed environment. Although the advantages of cloud computing are recognized in $\mathrm{CAD} / \mathrm{CAE} / \mathrm{CAM}$ industry, there are many different technological and research open 
problems, like cloud infrastructure models, interaction and communication methods, etc., that require further development for the transition and efficient use of cloud computing in CAx applications.

\section{Acknowledgment}

This research was supported by the Spanish Research Agency (AEI) and the European Regional Development Fund (ERDF) under the project CloudDriver4Industry TIN201789266-R.

\section{References}

Abdollahzadegan, A., Che Hussin, A. R., Moshfegh Gohary, M., \& Amini, M. (2013). The Organizational Critical Success Factors for Adopting Cloud Computing in SMEs [SSRN Scholarly Paper]. Social Science Research Network.

Agha, S. R., \& Alnahhal, M. J. (2012). Neural network and multiple linear regression to predict school children dimensions for ergonomic school furniture design. Applied Ergonomics, 43(6), 979-984. https://doi.org/10.1016/j.apergo.2012.01.007

Alcácer, V., \& Cruz-Machado, V. (2019). Scanning the Industry 4.0: A Literature Review on Technologies for Manufacturing Systems. Engineering Science and Technology, an International Journal, 22(3), 899-919. https:// doi.org/10.1016/j.jestch.2019.01.006

Aydin, M. (2015). Additive Manufacturing: Is It a New Era for Furniture Production? Journal of Mechanics Engineering and Automation, 5, 338-347.

Azariadis, P. (2012). Finite element analysis methods in footwear design. In The Science of Footwear (pp. 344-363). CRC Press. http://dx.doi.org/10.1201/b13021-19

Azariadis, P., Moulianitis, V., Alemany, S., González, J. C., Jong, P. de, Zande, M. van der, \& Brands, D. (2007). Virtual Shoe Test Bed: A Computer-Aided Engineering Tool for Supporting Shoe Design. Computer-Aided Design and Applications, 4(6), 741-750. https://doi.org/10.1080/16864360.2007.10738507

Azariadis, P., Papagiannis, P., \& Koutkalaki, Z. (2018). Integrating modern virtual engineering tools in footwear design and development. IOP Conference Series: Materials Science and Engineering, 459, 012072. https://doi.org/10.1088/1757-899X/459/1/012072

Barni, A., Corti, D., Pedrazzoli, P., \& Rovere, D. (2018). A Digital Fabrication Infrastructure Enabling Distributed Design and Production of Custom Furniture. In Customization 4.0 (pp. 173-190). Springer.

Barni, A., Corti, D., Pedrazzoli, P., Rovere, D., \& Lucisano, G. (2017). Mini-factories for Close-to-customer Manufacturing of Customized Furniture: From Concept to Real Demo. Procedia Manufacturing, 11, 854-862. https://doi.org/10.1016/j.promfg.2017.07.188

Bhuiyan, T., \& Hossain, M. S. (2015). University Hall Furniture Design based on Anthropometry: An Artificial Neural Network Approach. International Journal of Industrial and Systems Engineering, 20, 469-482. https://doi.org/10.1504/IJISE.2015.070184 
Braunstein, B., Schulze, N., Sanno, M., \& Brüggemann, G.-P. (2016). Comfort and plantar pressure pattern during running with prefabricated insoles. ISBS-Conference Proceedings Archive, 33.

CEN. (2013). Reference Architecture 2.0 for eBusiness harmonisation in Textile/Clotbing and Footwear sectors (Technical Report CWA 16667:2013 E; p. 372). European Committee for Standardization. http://ebiz-tcf.eu/wpcontent/uploads/2017/09/eBIZ_CWA_Reference_Architecture.pdf

Chang, S. H. (2016). Exploring the evolution of additive manufacturing industry: A study of stakeholder requirements and architectural analysis of Desktop three-dimensional printing Segment [PhD Thesis]. Massachusetts Institute of Technology.

Chen, M., Ma, Y., Song, J., Lai, C.-F., \& Hu, B. (2016). Smart Clothing: Connecting Human with Clouds and Big Data for Sustainable Health Monitoring. Mobile Networks and Applications, 21(5), 825-845. https://doi.org/10.1007/s11036-016-0745-1

Chituc, C.-M., Toscano, C., \& Azevedo, A. (2008). Interoperability in Collaborative Networks: Independent and industry-specific initiatives - The case of the footwear industry. Computers in Industry, 59(7), 741-757. https://doi.org/10.1016/j.compind.2007.12.012

Ciobanu, O., Soydan, Y., \& Hizal, S. (2012). Customized foot orthosis manufactured with 3D printers. Proceedings of IMS, 91-98.

Danese, G., Dulio, S., Giachero, M., Leporati, F., \& Nazzicari, N. (2011). A Novel Standard for Footwear Industrial Machineries. IEEE Transactions on Industrial Informatics, 7(4), 713-722. https://doi.org/10.1109/TII.2011.2166789

Davia, M., Jimeno-Morenilla, A., \& Salas, F. (2013). Footwear bio-modelling: An industrial approach. Computer-Aided Design, 45(12), 1575-1590.

Davia-Aracil, M., Hinojo-Pérez, J. J., Jimeno-Morenilla, A., \& Mora-Mora, H. (2018). 3D printing of functional anatomical insoles. Computers in Industry, 95, 38-53.

Davia-Aracil, M., Jimeno-Morenilla, A., \& Salas, F. (2016). A new methodological approach for shoe sole design and validation. The International Journal of Advanced Manufacturing Technology, 86(9-12), 3495-3516.

Daxhammer, K., Luckert, M., Doerr, M., \& Bauernhansl, T. (2019). Development of a Strategic Business Model Framework for Multi-Sided Platforms to Ensure Sustainable Innovation in Small and Medium-Sized Enterprises. Procedia Manufacturing, 39, 1354 1362. https://doi.org/10.1016/j.promfg.2020.01.322

Deng, Q., Gönül, S., Kabak, Y., Gessa, N., Glachs, D., Gigante-Valencia, F., DamjanovicBehrendt, V., Hribernik, K., \& Thoben, K.-D. (2019). An Ontology Framework for Multisided Platform Interoperability. In K. Popplewell, K.-D. Thoben, T. Knothe, \& R. Poler (Eds.), Enterprise Interoperability VIII (Vol. 9, pp. 433-443). Springer International Publishing. https://doi.org/10.1007/978-3-030-13693-2_36

Doyle, F., \& Cosgrove, J. (2019). Steps towards digitization of manufacturing in an SME environment. Procedia Manufacturing, 38, 540-547. https://doi.org/10.1016/j.promfg.2020.01.068

Ghobakhloo, M. (2018). The future of manufacturing industry: A strategic roadmap toward Industry 4.0. Journal of Manufacturing Technology Management, 29(6), 910-936. https://doi.org/10.1108/JMTM-02-2018-0057 
Guo, Z. X., Ngai, E. W. T., Yang, C., \& Liang, X. (2015). An RFID-based intelligent decision support system architecture for production monitoring and scheduling in a distributed manufacturing environment. International Journal of Production Economics, 159, 16-28. https://doi.org/10.1016/j.ijpe.2014.09.004

Hayes, B., \& Scassellati, B. (2014). Online Development of Assistive Robot Behaviors for Collaborative Manipulation and Human-Robot Teamwork. AAAI 2014.

Hinojo-Pérez, J. J., Davia-Aracil, M., Jimeno-Morenilla, A., Sánchez-Romero, J. L., \& Salas, F. (2016). Automation of the shoe last grading process according to international sizing systems. The International Journal of Advanced Manufacturing Technology, 85(1-4), 455467.

Hong, Y., Brunixaux, P., \& Chen, Y. (2018). Evaluation of Fashion Design Using Artificial Intelligence Tools. Artificial Intelligence for Fashion Industry in the Big Data Era, 245256. https://doi.org/10.1007/978-981-13-0080-6_12

Hu, L., Yang, J., Chen, M., Qian, Y., \& Rodrigues, J. J. P. C. (2018). SCAI-SVSC: Smart clothing for effective interaction with a sustainable vital sign collection. Future Generation Computer Systems, 86, 329-338. https://doi.org/10.1016/j.future.2018.03.042

Huang, P., Hsieh, Y., \& Mok, A. K. (2018). A Skill-Based Programming System for Robotic Furniture Assembly. 2018 IEEE 16th International Conference on Industrial Informatics, 355-361. https://doi.org/10.1109/INDIN.2018.8472030

Huang, R., Dai, N., Li, D., Cheng, X., Liu, H., \& Sun, D. (2018). Parallel non-dominated sorting genetic algorithm-II for optimal part deposition orientation in additive manufacturing based on functional features. Proceedings of the Institution of Mechanical Engineers, Part C: Journal of Mechanical Engineering Science, 232(19), 3384-3395. https://doi.org/10.1177/0954406217737105

Hull, T., \& Minarcin, M. A. (2016). Considerations in Collaborative Robot System Designs and Safeguarding. SAE International Journal of Materials and Manufacturing, 9(3), 545551.

Jimeno-Morenilla, A., García-Rodríguez, J., Orts, S., \& Davia-Aracil, M. (2016). GNG based foot reconstruction for custom footwear manufacturing. Computers in Industry, 75.

Jumani, M. S., Shaikh, S., \& Siddiqi, A. (2016). Cost modelling for fabrication of custommade foot orthoses using 3D Printing Technique. Sindh University Research Journal, 48(2).

Kang, H.-D. (2015). Analysis of furniture design cases using 3D printing technique. The Journal of the Korea Contents Association, 15(2), 177-186.

Kaplan, S., \& Karaman, C. (2019). Thermal comfort performances of cellulosic socks evaluated by a foot manikin system and moisture management tester. International Journal of Clothing Science and Technology, 31(2), 272-283. https://doi.org/10.1108/IJCST-062018-0080

Khan, M., Wu, X., Xu, X., \& Dou, W. (2017). Big data challenges and opportunities in the hype of Industry 4.0. 2017 IEEE International Conference on Communications (ICC), 16. https://doi.org/10.1109/ICC.2017.7996801

Knepper, R. A., Layton, T., Romanishin, J., \& Rus, D. (2013). IkeaBot: An autonomous multi-robot coordinated furniture assembly system. 2013 IEEE International Conference on Robotics and Automation, 855-862. https://doi.org/10.1109/ICRA.2013.6630673 
Kontogiorgos, D., Sibirtseva, E., Pereira, A., Skantze, G., \& Gustafson, J. (2018). Multimodal Reference Resolution In Collaborative Assembly Tasks. Proceedings of the 4th International Workshop on Multimodal Analyses Enabling Artificial Agents in Human-Machine Interaction, 38-42. https:// doi.org/10.1145/3279972.3279976

Koustoumpardis, P. N., \& Aspragathos, N. A. (2014). Intelligent hierarchical robot control for sewing fabrics. Robotics and Computer-Integrated Manufacturing, 30(1), 34-46. https://doi.org/10.1016/j.rcim.2013.08.001

Kumar Reddy, N. G. K., \& Rajeshwari, K. (2016). Interactive clothes based on Internet of Things using NFC and mobile application. 2016 Management and Innovation Technology International Conference, 104-107. https://doi.org/10.1109/MITICON.2016.8025237

Leaf, J., Wu, R., Schweickart, E., James, D. L., \& Marschner, S. (2018). Interactive design of periodic yarn-level cloth patterns. ACM Transactions on Graphics, 37(6), 202:1-202:15. https://doi.org/10.1145/3272127.3275105

León-Cabezas, M. A., Martínez-García, A., \& Varela-Gandía, F. J. (2017). Innovative functionalized monofilaments for 3D printing using fused deposition modeling for the toy industry. $\quad$ Procedia $\quad$ Manufacturing, $13, \quad 738-745$. https://doi.org/10.1016/j.promfg.2017.09.130

Li, Z., Xiong, G., Zhang, X., Shen, Z., Luo, C., Shang, X., Dong, X., Bian, G.-B., Wang, X., \& Wang, F.-Y. (2019). A GPU based parallel genetic algorithm for the orientation optimization problem in 3d printing. 2019-May, 2786-2792. https://doi.org/10.1109/ICRA.2019.8793989

Lipton, J. I., Schulz, A., Spielberg, A., Trueba, L., Matusik, W., \& Rus, D. (2018). Robot Assisted Carpentry for Mass Customization. 2018 IEEE International Conference on Robotics and Automation (ICRA), 1-8. https://doi.org/10.1109/icra.2018.8460736

Liu, J., Cui, H., Yang, Y., \& Qiao, Y. (2019). Design of Cloud Platform for Clothing Intelligent Manufacturing Based on RFID Technology. 201934rd Youth Academic Annual Conference of Chinese Association of Automation (YAC), 585-588. https://doi.org/10.1109/YAC.2019.8787613

Liu, K., Zeng, X., Bruniaux, P., Tao, X., Kamalha, E., \& Wang, J. (2018). Garment Fit Evaluation Using Machine Learning Technology. In S. Thomassey \& X. Zeng (Eds.), Artificial Intelligence for Fashion Industry in the Big Data Era (pp. 273-288). Springer Singapore. https://doi.org/10.1007/978-981-13-0080-6_14

Lloret-Climent, M., Nescolarde-Selva, J., Mora-Mora, H., Jimeno-Morenilla, A., \& AlonsoStenberg, K. (2019). Design of Products Through the Search for the Attractor. IEEE Access, 7, 60221-60227. https://doi.org/10.1109/ACCESS.2019.2915678

Luce, L. (2018). Artificial Intelligence for Fashion: How AI is Revolutionizing the Fashion Industry (1st ed. edition). Apress.

Mandolini, M., Brunzini, A., \& Germani, M. (2017). A collaborative web-based platform for the prescription of Custom-Made Insoles. Advanced Engineering Informatics, 33, 360-373. https://doi.org/10.1016/j.aei.2016.10.004

Mazak, A., \& Huemer, C. (2015). A standards framework for value networks in the context of Industry 4.0. 2015 IEEE International Conference on Industrial Engineering and Engineering Management, 1342-1346. https://doi.org/10.1109/IEEM.2015.7385866 
Mei, Q., Gu, Y., Zheng, Z., Yang, L., \& Fernandez, J. (2017). Foot shape, perceived comfort, and plantar pressure characteristics during long-distance running. Footwear Science, 9(sup1), S20-S22.

Meng, X., Ali, S. G., Li, P., Masood, A., Sheng, B., \& Ren, J. (2018). An Interior Decoration System via Virtual Reality and Artificial Intelligence. 2018 IEEE International Conference on Progress in Informatics and Computing, 221-225. https://doi.org/10.1109/PIC.2018.8706286

Michalitsi-Psarrou, A., Koussouris, S., Kontzinos, C., Markaki, O., Ntanos, C., Panopoulos, D., \& Psarras, J. (2019). Empowering Product Co-creation Approaches Through Business Interoperability Concepts: The Toy Industry Case. In K. Popplewell, K.-D. Thoben, T. Knothe, \& R. Poler (Eds.), Enterprise Interoperability VIII (Vol. 9, pp. 397-408). Springer International Publishing. https://doi.org/10.1007/978-3-030-13693-2_33

Morell-Giménez, V., Jimeno-Morenilla, A., \& García-Rodríguez, J. (2013). Efficient tool path computation using multi-core GPUs. Computers in Industry, 64(1), 50-56. https://doi.org/10.1016/j.compind.2012.09.009

Moreno, M., Charnley, F., Keely, D., \& Liddell, N. (2016). Shoe Lab White Paper. Figshare. https://doi.org/10.17862/cranfield.rd.4139856

Mourtzis, D., Doukas, M., Lalas, C., \& Papakostas, N. (2015). Cloud-based Integrated Shopfloor Planning and Control of Manufacturing Operations for Mass Customisation. Procedia CIRP, 33, 9-16. https://doi.org/10.1016/j.procir.2015.06.004

Muhuri, P. K., Shukla, A. K., \& Abraham, A. (2019). Industry 4.0: A bibliometric analysis and detailed overview. Engineering Applications of Artificial Intelligence, 78, 218-235. https://doi.org/10.1016/j.engappai.2018.11.007

Nakamura, M., Makihara, S., Sugiura, J.-I., \& Kamioka, Y. (2017). Dynamic optimization production system based on simulation integrated manufacturing and its application to mass production. International Journal of Automation Technology, 11(1), 56-66. https://doi.org/10.20965/ijat.2017.p0056

Navaei, J., Ghomi, S. M. T. F., Jolai, F., Shiraqai, M. E., \& Hidaji, H. (2013). Two-stage flowshop scheduling problem with non-identical second stage assembly machines. The International Journal of Advanced Manufacturing Technology, 69(9), 2215-2226. https://doi.org/10.1007/s00170-013-5187-3

Oztemel, E., \& Gursev, S. (2020). Literature review of Industry 4.0 and related technologies. Journal of Intelligent Manufacturing, 31(1), 127-182. https://doi.org/10.1007/s10845018-1433-8

Pallis, G. (2010). Cloud Computing: The New Frontier of Internet Computing. IEEE Internet Computing, 14(5), 70-73. https://doi.org/10.1109/MIC.2010.113

Papagiannis, P., Koutkalaki, Z., Azariadis, P., \& Papanikos, P. (2016). Definition and evaluation of plantar mechanical comfort for the support of footwear design. ComputerAided Design and Applications, 13(2), 162-172.

Petersen, E., Kidd, R., \& Pearce, J. (2017). Impact of DIY home manufacturing with 3D printing on the toy and game market. Technologies, 5(3), 45.

Ponis, S. T., Eijk, P. V. der, \& Masselos, V. (2012). Supply chain interoperability for enhancing e-business adoption by SMEs: A case study from the European clothing sector. 
International Journal of Business Information Systems, 10(4), 417. https://doi.org/10.1504/IJBIS.2012.048336

Popescu, D., Dragomir, M., Popescu, S., \& Neamțu, C. (2017). From Smart Products to Smart Manufacturing in Emerging Economies: Challenges and Insights from the Furniture Industry. Transactions on Engineering and Technology Research. https://doi.org/10.12783/dtetr/icpr2017/17589

Pozzi, R., \& Strozzi, F. (2018). How assembly systems are adopting the technologies of I40: A preliminary landscape. Proceedings of the Summer School Francesco Turco, 369-375.

Rauch, E., Unterhofer, M., \& Dallasega, P. (2018). Industry sector analysis for the application of additive manufacturing in smart and distributed manufacturing systems. Manufacturing Letters, 15, 126-131. https://doi.org/10.1016/j.mfglet.2017.12.011

Robert, J., Kubler, S., Traon, Y. L., \& Framling, K. (2016). O-MI/O-DF standards as interoperability enablers for Industrial Internet: A performance analysis. IECON 2016 - 42nd Annual Conference of the IEEE Industrial Electronics Society, 4908-4915. https://doi.org/10.1109/IECON.2016.7793138

Román-Ibáñez, V., Jimeno-Morenilla, A., \& Pujol-López, F. A. (2018). Distributed monitoring of heterogeneous robotic cells. A proposal for the footwear industry 4.0. International Journal of Computer Integrated Manufacturing, 31(12), 1205-1219. https://doi.org/10.1080/0951192X.2018.1529432

Shang, X., Shen, Z., Xiong, G., Wang, F.-Y., Liu, S., Nyberg, T. R., Wu, H., \& Guo, C. (2019). Moving from mass customization to social manufacturing: A footwear industry case study. International Journal of Computer Integrated Manufacturing, 32(2), 194-205. https://doi.org/10.1080/0951192X.2018.1550675

Shang, X., Wang, F.-Y., Xiong, G., Nyberg, T. R., Yuan, Y., Liu, S., Guo, C., \& Bao, S. (2018). Social manufacturing for high-end apparel customization. IEEE/CAA Journal of Automatica Sinica, 5(2), 489-500. https://doi.org/10.1109/JAS.2017.7510832

Solgi, E., Moattar Husseini, S. M., Ahmadi, A., \& Gitinavard, H. (2019). A hybrid hierarchical soft computing approach for the technology selection problem in brick industry considering environmental competencies: A case study. Journal of Environmental Management, 248. https://doi.org/10.1016/j.jenvman.2019.06.120

Spahiu, T., Grimmelsmann, N., Ehrmann, A., Shehi, E., \& Piperi, E. (2016). On the possible use of 3D printing for clothing and shoe manufacture. Proc. 7th Int. Conf. Text.

Suárez-Ruiz, F., Zhou, X., \& Pham, Q.-C. (2018). Can robots assemble an IKEA chair? Science Robotics, 3(17), eaat6385. https://doi.org/10.1126/scirobotics.aat6385

Tan, X., Xing, L., Cai, Z., \& Wang, G. (2020). Analysis of production cycle-time distribution with a big-data approach. Journal of Intelligent Manufacturing. https://doi.org/10.1007/s10845-020-01544-7

Tang, M., Tong, R., Narain, R., Meng, C., \& Manocha, D. (2013). A GPU-based Streaming Algorithm for High-Resolution Cloth Simulation. Computer Graphics Forum, 32(7), 21-30. https://doi.org/10.1111/cgf.12208

Terstyanszky, G., Kiss, T., Taylor, S., Anagnostou, A., Subira, M., Padula, G., Alonso, E. D. M., \& Rapun, J. M. M. (2016). Validating Scanned Foot Images and Designing Customized Insoles on the Cloud. 2016 49th Hawaii International Conference on System Sciences, 3288-3296. https://doi.org/10.1109/HICSS.2016.411 
Thomas, G., Chien, M., Tamar, A., Ojea, J. A., \& Abbeel, P. (2018). Learning Robotic Assembly from CAD. ArXiv:1803.07635 [Cs]. http://arxiv.org/abs/1803.07635

Triantafyllou, D., \& Aspragathos, N. (2018). Upper Layer Extraction of a Folded Garment Towards Unfolding by a Robot. In: Aspragathos N., Koustoumpardis P., Moulianitis V. (Eds) Advances in Service and Industrial Robotics.RAAD 2018. Mechanisms and Machine Science., 67, 597-604. https://doi.org/10.1007/978-3-030-00232-9_63

Triantafyllou, D., Koustoumpardis, P. N., \& Aspragathos, N. A. (2011). Model reference fuzzy learning force control for robotized sewing. 2011 19th Mediterranean Conference on Control Automation (MED), 1460-1465. https://doi.org/10.1109/MED.2011.5983137

Udayangani, J., Karunanayaka, I., \& Abeysooriya, R. (2019). Industry 4.0 Elements and Analytics for Garment Assembly Production Lines. 2019 Moratuwa Engineering Research Conference (MERCon), 745-750. https://doi.org/10.1109/MERCon.2019.8818882

Vasseur, R. (2017). What is Distributed Manufacturing? Link3D. https://link3d.co/blog/what-is-distributed-manufacturing

Vassilev, T. I. (2016). Garment Simulation and Collision Detection on a Mobile Device. Int. J. Mob. Comput. Multimed. Commun., 7(3), 1-15. https://doi.org/10.4018/IJMCMC.2016070101

Vidal, J. C., Mucientes, M., Bugarín, A., \& Lama, M. (2011). Machine scheduling in custom furniture industry through neuro-evolutionary hybridization. Applied Soft Computing, 11(2), 1600-1613. https://doi.org/10.1016/j.asoc.2010.04.020

Villa, A., \& Taurino, T. (2019). SME Innovation and Development in the Context of Industry 4.0. Procedia Manufacturing, 39, 1415-1420. https://doi.org/10.1016/j.promfg.2020.01.311

Wang, C.-C., Yang, C.-H., Wang, C.-S., Xu, D., \& Huang, B.-S. (2019). Artificial neural networks in the selection of shoe lasts for people with mild diabetes. Medical Engineering E Physics, 64, 37-45. https://doi.org/10.1016/j.medengphy.2018.12.014

Wang, J., Yang, J., Zhang, J., Wang, X., \& Zhang, W. C. (2018). Big data driven cycle time parallel prediction for production planning in wafer manufacturing. Enterprise Information Systems, 12(6), 714-732. Scopus. https://doi.org/10.1080/17517575.2018.1450998

Wang, Y., Ma, H.-S., Yang, J.-H., \& Wang, K.-S. (2017). Industry 4.0: A way from mass customization to mass personalization production. Advances in Manufacturing, 5(4), 311320.

Wienbruch, T., Leineweber, S., Kreimeier, D., \& Kuhlenkötter, B. (2018). Evolution of SMEs towards Industrie 4.0 through a scenario based learning factory training. Procedia Manufacturing, 23, 141-146. https://doi.org/10.1016/j.promfg.2018.04.007

Xidias, E., Koutkalaki, Z., Papagiannis, P., Papanikos, P., \& Azariadis, P. (2015). Foot Plantar Pressure Estimation Using Artificial Neural Networks. In: Bouras A., Eynard B., Foufou S., Thoben KD. (Eds) Product Lifecycle Management in the Era of Internet of Things. PLM 2015. IFIP Advances in Information and Communication Technology, 467. https://doi.org/10.1007/978-3-319-33111-9_3

Xiong, X., Yuan, Y., Fang, L., Liu, H., \& Wu, Z. (2018). Status and Development Trends of Intelligent Manufacturing in China's Furnishings Industry. Forest Products Journal, 68(3), 328-336. 
Xu, Y., Thomassey, S., \& Zeng, X. (2018). AI for Apparel Manufacturing in Big Data Era: A Focus on Cutting and Sewing. In S. Thomassey \& X. Zeng (Eds.), Artificial Intelligence for Fashion Industry in the Big Data Era (pp. 125-151). Springer Singapore. https://doi.org/10.1007/978-981-13-0080-6_7

Xue, C., Dong, H., Zhang, M., \& Pan, Z. (2017). Real-time Simulation on Virtual Dressing Based On Virtual Human Body Model. Xitong Fangzhen Xuebao / Journal of System Simulation, 29(11), 2847-2855. Scopus. https://doi.org/10.16182/j.issn1004731x.joss.201711034

Yan, H., Zeng, X., Brunixaux, P., \& Chen, Y. (2018). Evaluation of Fashion Design Using Artificial Intelligence Tools (pp. 245-256). https://doi.org/10.1007/978-981-13-0080-6_12

Zakharkevich, O., Zhylenko, T., Koshevko, Y., Kuleshova, S., Ditkovska, O., \& Shvets, G. (2018). Expert system to select the fabrics for transformable garments. Vlakna a Textil, 25, $105-112$.

Zang, H., Liu, Z., Chai, Y., Liu, T., \& Zhou, K. (2018). Real-Time Collision Detection Method for Fluid and Cloth. Journal of Computer-Aided Design and Computer Graphics, 30(4), 602-610. Scopus. https://doi.org/10.3724/SP.J.1089.2018.16528

Zawadzki, P., \& Żywicki, K. (2016). Smart product design and production control for effective mass customization in the Industry 4.0 concept. Management and Production Engineering Review, 7(3), 105-112.

Zeylikman, S., Widder, S., Roncone, A., Mangin, O., \& Scassellati, B. (2018). The HRCModel Set for Human-Robot Collaboration Research. 1845-1852. https://doi.org/10.1109/IROS.2018.8593858

Zhang, L., Luo, Y., Tao, F., Li, B. H., Ren, L., Zhang, X., Guo, H., Cheng, Y., Hu, A., \& Liu, Y. (2014). Cloud manufacturing: A new manufacturing paradigm. Enterprise Information Systems, 8(2), 167-187. https://doi.org/10.1080/17517575.2012.683812

Zhao, Z., \& Ma, X. (2018). A Compensation Method of Two-Stage Image Generation for Human-AI Collaborated In-Situ Fashion Design in Augmented Reality Environment. 2018 IEEE International Conference on Artificial Intelligence and Virtual Reality, 76-83. https://doi.org/10.1109/AIVR.2018.00018

Zheng, P., Lu, Y., Xu, X., \& Xie, S. Q. (2017). A system framework for OKP product planning in a cloud-based design environment. Robotics and Computer-Integrated Manufacturing, 45, 73-85. https://doi.org/10.1016/j.rcim.2016.04.001

Zheng, T., Ardolino, M., Bacchetti, A., \& Perona, M. (2019). Enabling technologies, impacts and challenges of "Industry 4.0" in the manufacturing context: Some insights from a preliminary literature review. Proceedings of XXIV Summer School "Francesco Turco" Industrial Systems Engineering, 1, 27-33.

Zissis, D., Lekkas, D., Azariadis, P., Papanikos, P., \& Xidias, E. (2017). Collaborative CAD/CAE as a cloud service. International Journal of Systems Science: Operations E Logistics, 4(4), 339-355. https://doi.org/10.1080/23302674.2016.1186237 